\title{
Meta-analysis of antiviral protection of white spot syndrome virus vaccine to the shrimp
}

\author{
Shu-Ying Feng ${ }^{\mathrm{a} \dagger}$, Gao-Feng Liang ${ }^{\mathrm{a} \dagger}$, Zheng-Shun $\mathrm{Xu}^{\mathrm{a}}$, Ai-Fang Li ${ }^{\mathrm{a}}$, Jing-Xia Du ${ }^{\mathrm{a}}$, Guan-Nan \\ Song $^{\text {a }, \text { Shai-Yu Ren }}{ }^{\mathrm{a}}$, Yu-Lin Yang ${ }^{\mathrm{a}}$, Guanglong Jiang ${ }^{\mathrm{b}, \mathrm{c}_{*}}$ \\ ${ }^{a}$ Medical College, Henan University of Science and Technology, Luoyang, Henan 471023, China \\ $b$ \\ Center for Computational Biology and Bioinformatics, Indiana University School of Medicine, \\ Indiana 46202 USA \\ $c$ \\ Department of BioHealth Informatics, Indiana University-Purdue University Indianapolis, Indiana \\ 46202 USA
}

$\uparrow$ These authors contributed equally to this work.

*Corresponding author

Center for Computational Biology and Bioinformatics,

Indiana University School of Medicine,

Indiana 46202, USA

Department of BioHealth Informatics,

Indiana University Purdue University Indianapolis,

Indiana 46202 USA

E-mail: ggjiang@iu.edu

Abbreviations

WSSV, white spot syndrome virus; RNAi, RNA interference; E. coli, Esherichia coli; B. subtili, Bacillus subtili; D. salina, Dunaliella salina;

This is the author's manuscript of the article published in final edited form as:

Feng, S.-Y., Liang, G.-F., Xu, Z.-S., Li, A.-F., Du, J.-X., Song, G.-N., ... Jiang, G. (2018). Meta-analysis of antiviral protection of white spot syndrome virus vaccine to the shrimp. Fish \& Shellfish Immunology, 81, 260-265. https://doi.org/10.1016/j.fsi.2018.07.023 
Abstract: Currently, white spot syndrome virus (WSSV) is one of the most serious pathogens that impacts shrimp farming around the world. A WSSV vaccine provides a significant protective benefit to the host shrimp. Although various types of vaccines against WSSV have emerged, the immune effects among them were not compared, and it remains unclear which type of vaccine has the strongest protective effect. Meanwhile, due to the lack of effective routes of administration and immunization programs, WSSV vaccines have been greatly limited in the actual shrimp farming. To answer these questions, this study conducted a comprehensive meta-analysis over dozens of studies and compared all types WSSV vaccines, which include sub-unit protein vaccines, whole virus inactivated vaccines, DNA vaccines and RNA-based vaccines. The results showed that the RNA-based vaccine had the highest protection rate over the other three types of vaccines. Among the various sub-unit protein vaccines, VP26 vaccine had the best protective effects than other sub-unit protein vaccines. Moreover, this study demonstrated that vaccines expressed in eukaryotic hosts had higher protection rates than that of prokaryotic systems. Among the three immunization modes (oral administration, immersion and injection) used in monovalent protein vaccines, oral administration had the highest protection rate. In natural conditions, shrimp are mostly infected by the virus orally. These results provide a guide for exploration of a novel WSSV vaccine and help facilitate the application of WSSV vaccines in shrimp farming.

Key words: WSSV; Vaccine type; Immune program; Virus gene; Protection rate; Meta-analysis 


\section{Introduction}

Since the outbreak in shrimp in the 1990s, white spot syndrome virus (WSSV) has become the most virulent pathogen in the industry and impacts shrimp farming globally each year [1]. As a result, the development of viral vaccine has become one of intense focus of research in this field. So far, research in WSSV vaccine has made great progress and a variety types of vaccines have emerged, such as sub-unit protein vaccine [2], inactivated whole virus vaccine [3], DNA vaccine [4], RNA-based vaccine [5] and so on. These vaccines have proven that they can significantly enhance the immune response of the host shrimp and provide a significant protective effect in shrimp [6-9]. However, the protection rate among vaccines has not been compared. For the same viral protein, taking VP28 as an example, different types of vaccines have different immune effects in the host [10-12]. Additionally, even with same vaccine, different modes of immunization have different immune protective effects in animals $[7,8,13]$. Furthermore, different immunization times or attack times also result in different immune effects for the same protein vaccine $[14,15]$. Conflicting conclusions were also observed between different studies $[16,17]$. Furthermore, the immunization program, which includes the immune time and length, time of virus attack, mode of virus attacks and so on has a decisive effect on the immune effects. Although a WSSV vaccine has the potential significantly benefit the host shrimp, its practical application is heavily hindered by the lack of efficient and uniform immunization programs. To solve these above-mentioned issues, this study conducted a comprehensive meta-analysis for all kinds of current WSSV vaccines.

\section{Materials and Methods}

\subsection{Search strategy and data retrieval}

All the relevant studies were retrieved using the search keywords of 'white spot syndrome virus' plus 'vaccine', or 'immune', or 'protection', or 'antiviral', or ‘control', or 'prevention' etc. Search domains came from the English scientific publication databases such as the PubMed, SCI database, Elsevier, and the Springer; Chinese scientific databases like the CQVIP database, Wanfang database, China national knowledge infrastructure (CNKI), Chinese science citation database (CSCD), and also 
from the other public search engines, such as Google scholar and Web of Science. There were 178 articles related to these keywords in which 98 references were determined to be relevant after review. After analysis, 54 publications containing protective effects fit the criteria for inclusion. All the data used in this study were extracted from the results of these original research papers. The WSSV vaccines were divided into four main categories; viral sub-unit vaccines, inactivated whole virus vaccines, DNA vaccines, and RNA-based vaccines. The characteristics of each vaccine were summarized respectively in supplementary data $1-4$, with regard to the different types of vaccine, forms of the protein subunits, modes of administration, protection rate, and other relevant data [3-10, $12-14,16-55]$.

\subsection{Statistical analysis}

The outcome used in this study was the proportion of protection rate against WSSV infection among the different types and modes of vaccines. A Freeman-Tukey transformation [56] was applied to the protection rate to stabilize the variance and make the 0 to 1 ranged proportion more suitable for the statistical comparisons among groups. Heterogeneity was assessed using the Cochran's Q statistics, and subset and regression analysis were conducted to explore potential sources of heterogeneity. A multivariate logistic regression was conducted to model the effects of different types of vaccines and virus attack modes. The analyses were conducted in statistical environment $\mathrm{R}$ (version 3.4.0) using metafor package [57].

\section{Results}

\subsection{Meta-analysis of overall protection rates for main types of vaccines}

To estimate the average protective effects for each type of vaccine, we first applied the meta-analysis random-effects model to protection rates of studies in the four main vaccine subtypes separately. Figure 1 shows the forest plot for protective rates of each study, and the weighted estimate of average protection rates in the context of a random-effects model for each subtype of vaccines. The weighted protection rates for each one of those four subtypes of vaccines, ranking from high to low, are RNA-based vaccine (Fig 1D, 80.18\%), inactivated whole virus vaccine (Fig 1B, 65.29\%), DNA 
vaccine (Fig 1C, 59.00\%) and sub-unit protein vaccine (Fig 1A bottom, 55.88\%) respectively. The monovalent (Fig 1A top) and polyvalent (Fig 1A middle) sub-unit protein vaccines have average protection rates $56.12 \%$ and $55.20 \%$, respectively. Among those types of vaccines, the RNA-based vaccine has the highest protection rates and the smallest heterogeneity. Conversely, monovalent protein vaccines (Fig 1A top) and DNA vaccines (Fig 1C) have a very large heterogeneity (p<0.001), and polyvalent vaccines (Fig 1A middle) have the lowest average protection rate $(55.20 \%)$. Figure 1E wholly shows the side by side comparison of the estimated protection rates for monovalent, polyvalent, while virus, DNA vaccine and RNA-based vaccines. 
Fig. 1A

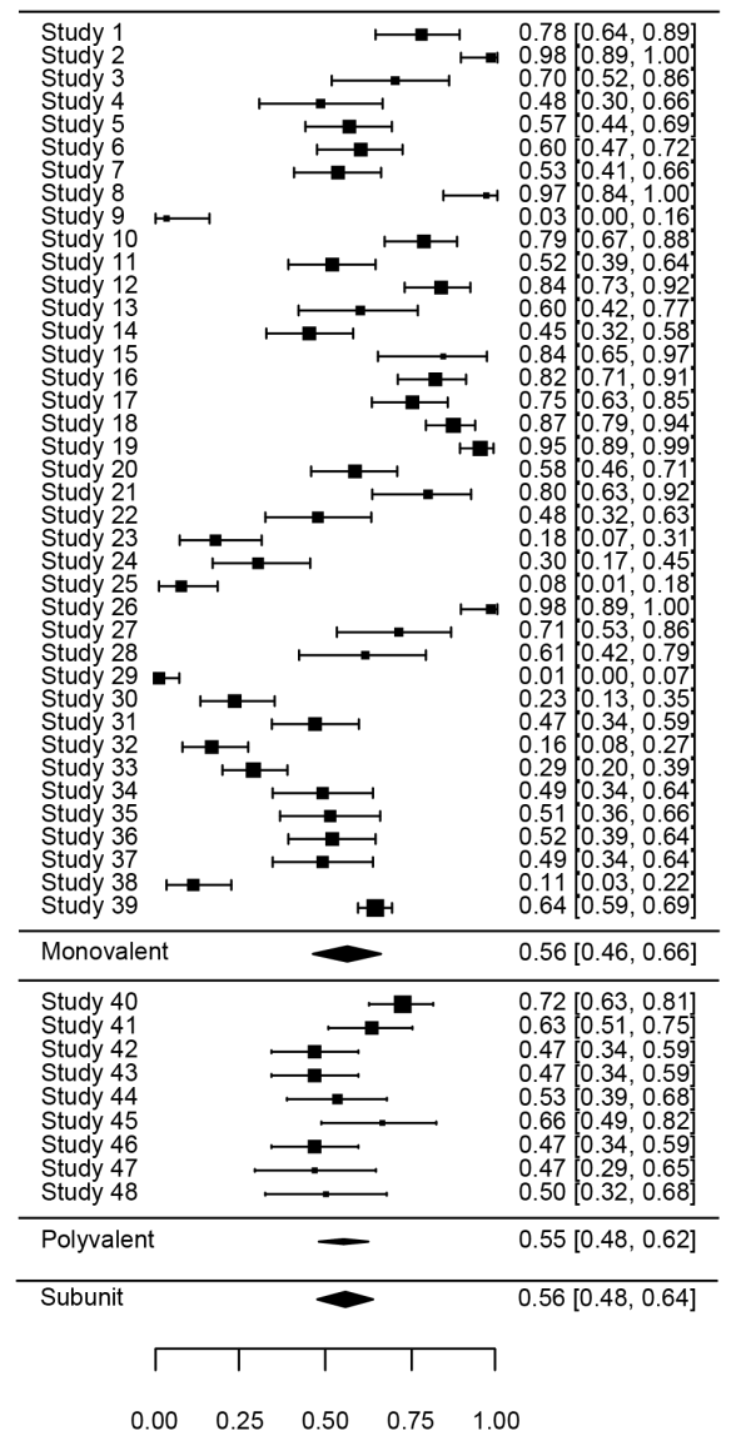

Fig. 1B

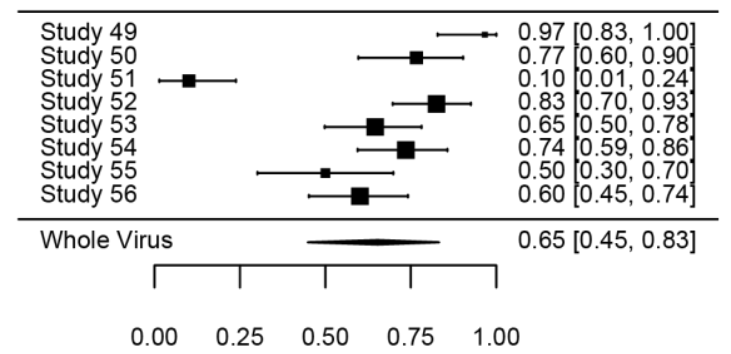

Fig. 1C

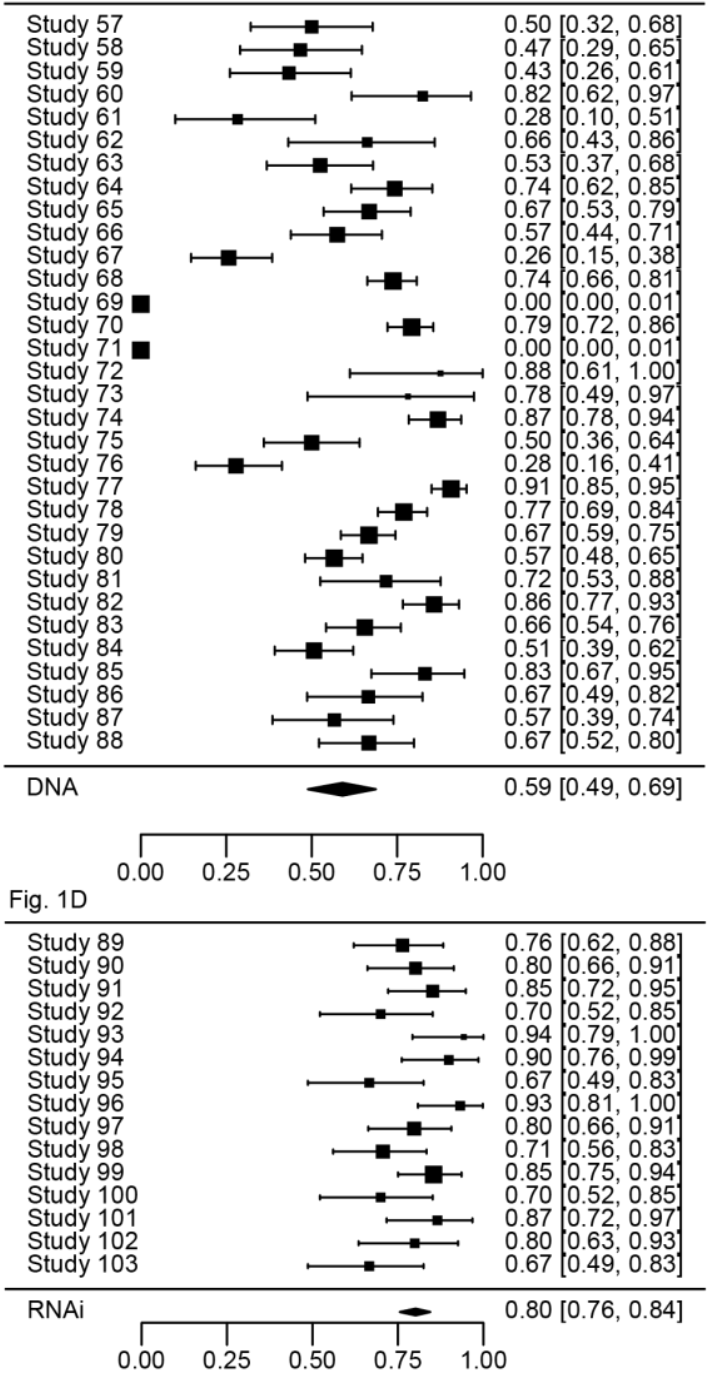

Fig. 1E

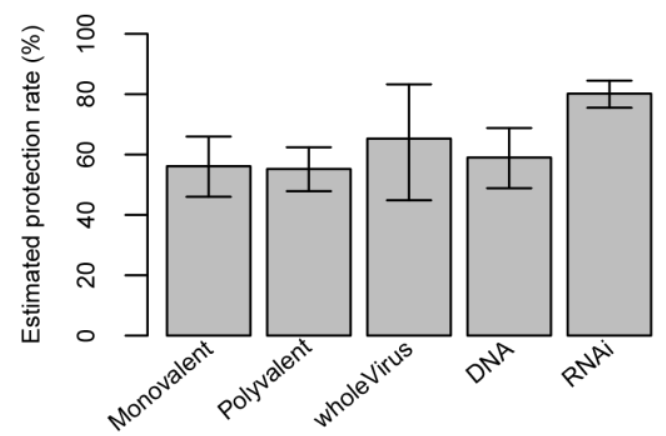

Fig. 1. Forest plot of protective rates for four main vaccine types and the weighted estimated average protection rates. (1A)

Subunit vaccines (top: monovalent vaccines; middle: polyvalent vaccines; bottom: estimated average protection rate for subunit vaccines); (1B) Whole virus inactivated vaccines; (1C) DNA vaccines; (1D) RNA technology-based vaccines; (1E) Estimated protection rates with confidence intervals for each type of vaccine. 


\subsection{Monovalent Vaccines}

\subsubsection{Subgroup analysis}

Among the subtype of vaccines, monovalent vaccines have the largest number of published studies (n=39) and the greatest heterogeneity. $64 \%$ of monovalent vaccine studies were conducted with the protein VP28 (Fig 2A), with an average protection rate of $63.21 \%$, while still a high level of heterogeneity $(\mathrm{p}<0.001)$. There are only 3 studies conducted with VP26 protein (Fig $2 \mathrm{~B})$, which had the highest estimated protection rate $(80.48 \%)$. 7 studies using VP19 proteins revealed the lowest average protection rate of $28.49 \%$ (Fig 2C). Beyond those three proteins, little publish research has been conducted (Fig 2D) and that data was not meta-analyzed here. Among the 25 studies using VP28, 14 of them expressed this protein in E. coli had relatively low estimated protection rate (52.32\%) and high heterogeneity; on the contrary, 11 studies using other expression hosts such as B. subtilis and Baculovirus had a higher estimated protection rate (75.73\%, Fig. 3).The meta-analysis above showed that the type of proteins used in vaccines and expression host contributed to part of the heterogeneity

(Fig 2 and Fig 3).

Fig. $2 \mathrm{~A}$

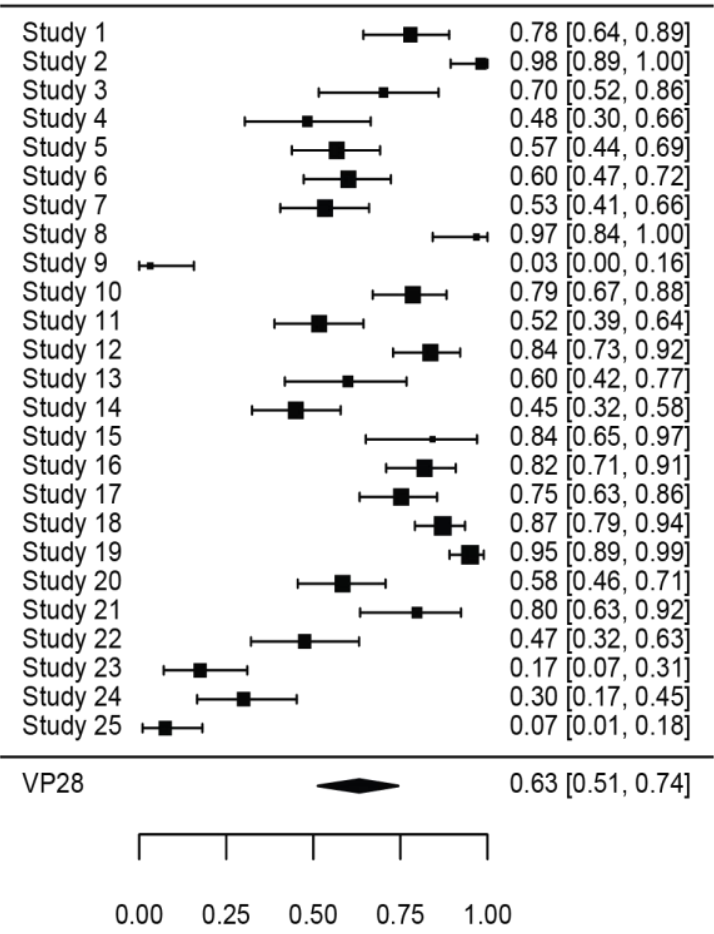

Fig. 2B

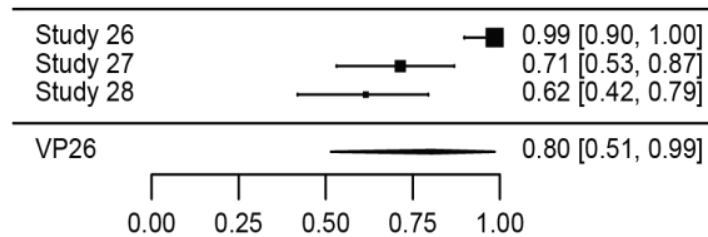

Fig. 2C

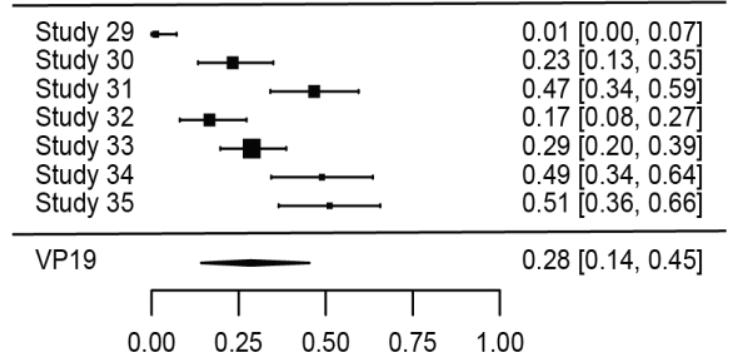

Fig. 2D

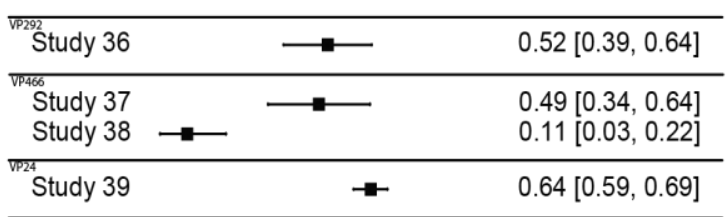

Fig. 2. Forest plot of average protection rates for different monovalent vaccines. (2A) Monovalent VP28 vaccine; (2B) 


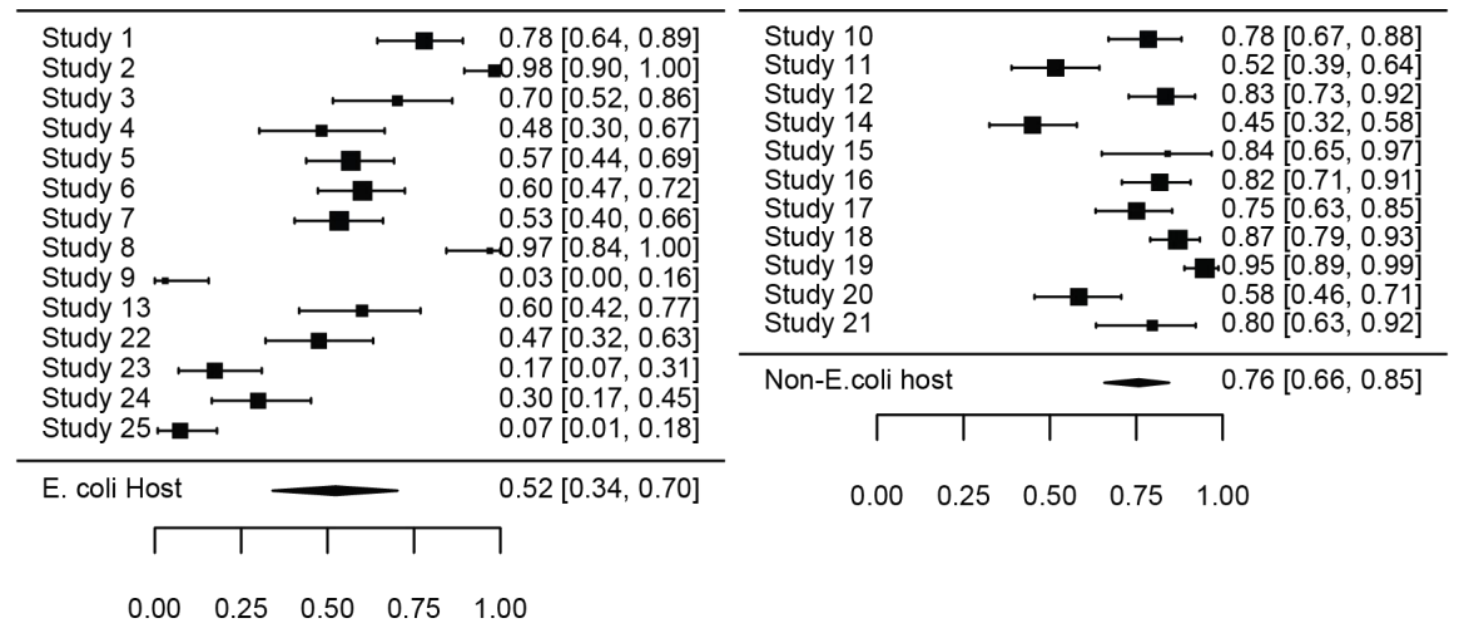

Fig. 3. Forest plot of average protection rates for monovalent vaccine studies. (Left) shown that conducted on the host of $E$. coli; (Right) shown that conducted on the host of non-E. coli.

\subsubsection{Regression analysis}

The logistic regression was applied to the monovalent vaccine data including 39 studies and 2,205 experimental units. Univariate regression analysis confirmed that all five factors are significantly associated with protection rates (Table 1), while in the multivariate analysis, protein form, immunization mode, and virus attack mode were no longer significantly associated with protection rates because of the collinearity among them (Table 2). From the univariate analysis, VP26 had a higher protection rate than protein VP28, while VP19 and VP466 had relatively low protection rates compared to VP28. VP292 also had an inferior protection rate compared to VP28, while VP24 was not different from VP28.

Table 1 Univariate analysis of factors that associate with protection rate

\begin{tabular}{cc}
\hline Variables & P value \\
\hline Protein (VP28, VP19, VP24, VP26, VP292 and VP466) & $\mathrm{P}<2.2 \times 10^{-16}$ \\
Proteins Form (Purified, Transgenic and Others) & $2.8 \times 10^{-15}$ \\
Expression host (E. coli and Others) & $4.0 \times 10^{-8}$ \\
Immunization mode (Oral, Immersion and Injection) & $2.4 \times 10^{-8}$ \\
Virus attack mode (Oral, Immersion and Injection) & $7.5 \times 10^{-6}$ \\
\hline
\end{tabular}


Table 2 Multivariate analysis of factors associate with protection rate

\begin{tabular}{cc}
\hline Variables remain significant & P value \\
\hline Protein (VP28, VP19, VP24, VP26, VP292 and VP466) & $\mathrm{P}<2.2 \times 10^{-16}$ \\
Expression host (E. coli and Others) & $\mathrm{P}<2.2 \times 10^{-16}$ \\
\hline
\end{tabular}

The mentioned-above trends can also be found in the boxplot of protection rates against every protein (Fig 4A). Among three protein forms, purified protein has a significantly lower protection rate than transgenic or other forms (Fig 4B). Fig 4C suggests that protein vaccines expressed in E. coli had lower protection rate than other expression hosts. As to the effect of immunization modes, Fig 4D shows that oral differs significant from immersion and injection in protection rates, which had the highest protection rate among the three immunization modes. On the contrary, regarding the impact of virus attack mode, oral attack had inferior protection rate compared to immersion, but was not significantly different from injection ( Fig 4E).
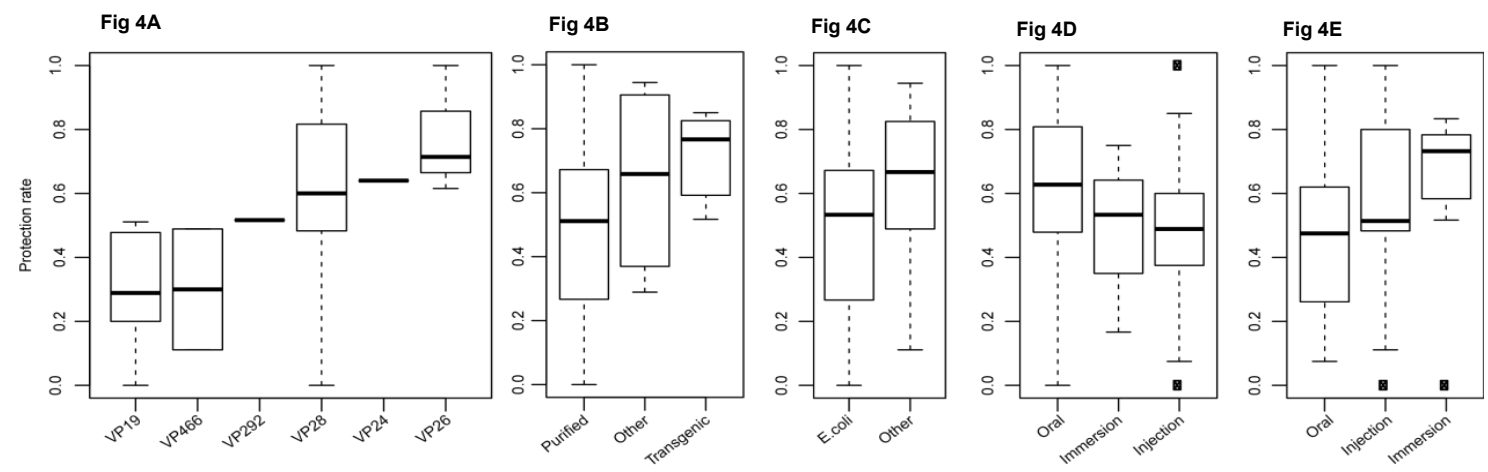

Fig. 4. Box plot of protection rates for studies grouped by different factors. (4A) Proteins; (4B) Protein forms; (4C)

Expression hosts; (4D) Immunization mode; (4E) Virus attack mode.

\subsection{The best practices for RNA-based vaccine}

Compared to other types of vaccines, RNA-based vaccines had the best protection rate and were homogeneous across studies (Fig 1D and 1E). To find the best practices for RNA vaccines, a logistic regression mode was adopted to further investigate the impact of dsRNA target genes, immunization mode, and virus attack mode on protection rate of RNA-based vaccines. Compared to other genes, the 
combination of PmRab7 and rr2 genes has the best protection rate of 95\%. However, the differences in protective effects between PmRab7+rr2 and other genes investigated in those studies were not statistically significantly $(\mathrm{p}=0.10)$. Oral immunization performed significantly worse than injection $(\mathrm{p}=0.03)$ in immunization mode, while there was no significant difference observed between oral and injection virus attack mode $(\mathrm{p}=0.3)$.

\section{Discussion}

Through the first-time analysis with the meta tool, this study not only compared the protection rates of different types of vaccines, but also analyzed the protective effects of different protein subunit vaccines. Among the four types of vaccines, RNA-based vaccines have the highest protection rates over the other types of vaccines. The reason for this may be that RNA-based vaccines work directly at the transcriptional level, which targets the early stages of viral replication, not at the DNA or protein level $[51,52,58]$. Among the various subunit proteins vaccines, VP26 vaccine showed the best protective effect, not the most studied VP28 vaccine as might be expected. This may be due to the heterogeneity among studies of VP28 vaccine, as some studies had relatively lower protection rates and make the overall estimated average protection rate low. Multiple factors could have contributed to the variation of protection rate, e.g. immunization time, vaccine dose, and immunization route. However, the source of heterogeneity cannot be fully elucidated due to the limited details in the reports. This result needs to be further investigated by more comprehensive comparison that make the all other conditions consistent in the future vaccine studies.

Due to the fact of lack of effective routes of administration and immunization program, WSSV vaccine still has not been fully utilized in the actual production of aquaculture.For this reason, this study further investigates effects of some factors that potentially impact vaccine protection rate. Through comparison of eukaryotic system and prokaryotic system, the results demonstrated that protein vaccines expressed in eukaryotic hosts had a higher protection rate than that in prokaryotic $E$. coli $[10,25,26]$. Among the three immunization modes used in subunit vaccines, oral mode differs significantly from immersion and injection, and has the highest protection rate. This mode is also more suitable for operation and application of a vaccine in the practical breeding of shrimp. As to the virus attack mode, the results showed that the mortality caused by oral infection is similar to that of the injection route, but worse than that of the immersion mode of virus attack $[7,16,17]$. So, it implies that shrimps are primarily infected with the virus by oral means under natural conditions. Furthermore, it suggests that disinfecting the water environment is conducive to the prevention and control of WSSV. 
In addition, the immunization dose of vaccine and the challenge dose of the virus have a crucial effect on the immune effect. However, since the specific immune dose or challenge dose is not well stated $[14,25,55]$, or the unit of measurement is not consistent in many references $[59,60]$, these factors were not taken into account in the current study. With more comprehensive statistical data, the study can further investigate in more details. In general, establishment of a high-efficiency immune program could advance the progress of actual application of WSSV vaccines in shrimp farming, and provide reference for the control of other viral diseases in crustaceans.

\section{Conflict of interest}

The authors declare no conflict of interest.

\section{Acknowledgments}

This work was supported by the National Natural Science Foundation of China (No. 31571289), the Young Backbone Teacher Project of Henan Province Universities, China (No. 2012GGJS-080). The authors gratefully acknowledge Laura Gardner for modifying and polishing this manuscript.

\section{References}

[1] C.H. Seibert, A.R. Pinto, Challenges in shrimp aquaculture due to viral diseases: distribution and biology of the five major penaeid viruses and interventions to avoid viral incidence and dispersion, Braz. J. Microbiol. 43 (2012) 857-864.

[2] K.C. Pham, H.T. Tran, C. Van Doan, P.H. Le, A.T. Van Nguyen, H.A. Nguyen, et al., Protection of Penaeus monodon against white spot syndrome by continuous oral administration of a low concentration of Bacillus subtilis spores expressing the VP28 antigen, Lett. Appl. Microbiol. 64 (2017) 184-191.

[3] N.S. Sudheer, G. Poulose, A. Thomas, K. Viswanath, A. Kulkarni, R.B. Narayanan, et al., Expression profile of bio-defense genes in Penaeus monodon gills in response to formalin inactivated white spot syndrome virus vaccine, Antiviral. Res. 117 (2015) 60-68.

[4] T. Rattanarojpong, S. Khankaew, P. Khunrae, R. Vanichviriyakit, K. Poomputsa, Recombinant baculovirus mediates dsRNA specific to rr2 delivery and its protective efficacy against WSSV infection, J. Biotechnol. 229 (2016) 44-52.

[5] R.R. Alenton, H. Kondo, I. Hirono, M.B. Maningas, Gene silencing of VP9 gene impairs WSSV infectivity on 
Macrobrachium rosenbergii, Virus Res. 214 (2016) 65-70.

[6] I.S. Bright Singh, M. Manjusha, S.S. Pai, R. Philip, Fenneropenaeus indicus is protected from white spot disease by oral administration of inactivated white spot syndrome virus, Dis. Aquat. Organ. 66 (2005) 265-270.

[7] J. Satoh, T. Nishizawa, M. Yoshimizu, Protection against white spot syndrome virus (WSSV) infection in kuruma shrimp orally vaccinated with WSSV rVP26 and rVP28, Dis. Aquat. Organ. 82 (2008) 89-96.

[8] J.Y. Yang, C.I. Chang, K.F. Liu, J.R. Hseu, L.H. Chen, J.M. Tsai, Viral resistance and immune responses of the shrimp Litopenaeus vannamei vaccinated by two WSSV structural proteins, Immunol. Lett. 148 (2012) 41-48.

[9] Y.M. Sun, F.H. Li, Y.H. Chi, J.H. Xiang, Enhanced resistance of marine shrimp Exopalamon carincauda Holthuis to WSSV by injecting live VP28-recombinant bacteria, Acta Oceano.1 Sinica 32 (2013) 52-58.

[10] S. Feng, W. Feng, L. Zhao, H. Gu, Q. Li, K. Shi, et al., Preparation of transgenic Dunaliella salina for immunization against white spot syndrome virus in crayfish. Arch. Virol. 159 (2014) 519-525.

[11] S. Vimal, S. Abdul Majeed, G. Taju, K.S. Nambi, N. Sundar Raj, N. Madan, et al., Chitosan tripolyphosphate (CS/TPP) nanoparticles: preparation, characterization and application for gene delivery in shrimp, Acta Tropica 128 (2013) $486-493$.

[12] T. Thammasorn, P. Sangsuriya, W. Meemetta, S. Senapin, S. Jitrakorn, T. Rattanarojpong, et al., Large-scale production and antiviral efficacy of multi-target double-stranded RNA for the prevention of white spot syndrome virus (WSSV) in shrimp, BMC Biotechnol. 15 (2015)110.

[13] M.S. Syed, J. Kwang, Oral Vaccination of baculovirus-expressed VP28 displays enhanced protection against white spot syndrome virus in Penaeus monodon, PLoS One 6 (2011) e26428.

[14] C.M. Caipang, N. Verjan, E.L. Ooi, H. Kondo, I. Hirono, T. Aoki, et al., Enhanced survival of shrimp, Penaeus (Marsupenaeus) japonicus from white spot syndrome disease after oral administration of recombinant VP28 expressed in Brevibacillus brevis, Fish Shellfish Immunol. 25 (2008) 315-320.

[15] R. Mavichak, T. Takano, H. Kondo, I. Hirono, S. Wada, K. Hatai, et al., The effect of liposome-coated recombinant protein VP28 against white spot syndrome virus in kuruma shrimp, Marsupenaeus japonicus, J. Fish Dis. 33 (2010) 69-74.

[16] R.K. Jha, Z.R. Xu, J. Shen, S.J. Bai, J.Y. Sun, W.F. Li, The efficacy of recombinant vaccines against white spot syndrome virus in Procambarus clarkii, Immunol. Lett. 105 (2006) 68-76.

[17] Z. Qiu, Q. Liu, J. Huang, Efficiency of two fragments of VP28 against white spot syndrome virus in Litopenaeus vannamei. Aquaculture 338 (2012) 2-12.

[18] J. Witteveldt, C.C. Cifuentes, J.M. Vlak, M.C. Van Hulten, Protection of Penaeus monodon against white spot syndrome 
virus by oral vaccination, J. Virol. 78 (2004) 2057-2061.

[19] N. Rout, S. Kumar, S. Jaganmohan, V. Murugan, DNA vaccines encoding viral envelope proteins confer protective immunity against WSSV in black tiger shrimp, Vaccine 25 (2007) 2778-2786.

[20] J. Robalino, C.L. Browdy, S. Prior, A. Metz, P. Parnell, P. Gross, et al., Induction of antiviral immunity by double stranded RNA in a marine invertebrate, J. Virol. 78 (2004) 10442-10448.

[21] L.L. Fu, W.F. Li, H.H. Du, W. Dai, Z.R. Xu, Oral vaccination with envelope protein VP28 against white spot syndrome virus in Procambarus clarkii using Bacillus subtilis as delivery vehicles, Lett. Appl. Microbiol. 46 (2008) 581-586.

[22] L.L. Fu, J.B. Shuai, Z.R. Xu, J.R. Li, W.F. Li, Immune responses of Fenneropenaeus chinensis against white spot syndrome virus after oral delivery of VP28 using Bacillus subtilis as vehicles, Fish Shellfish Immunol. 28 (2010) 49-55.

[23] G. Solís-Lucero, K. Manoutcharian, J. Hernández-López, F. Ascencio, Injected phage displayed VP28 vaccine reduces shrimp Litopenaeus vannamei mortality by white spot syndrome virus infection, Fish Shellfish Immunol. 55 (2016) $401-406$.

[24] S. Syed Musthaq, S. Madhan, A.S. Sahul Hameed, J. Kwang, Localization of VP28 on the baculovirus envelope and its immunogenicity against white spot syndrome virus in Penaeus monodon, Virology 391 (2009) 315-324.

[25] R.K. Jha, Z.R. Xu, S.J. Bai, J.Y. Sun, F.L. Wei, J. Shen, Protection of Procambarus clarkii against white spot syndrome virus using recombinant oral vaccine expressed in Pichia pastoris, Fish Shellfish Immunol. 22 (2007) 295-307.

[26] K.Q. Wei, J.X. Yang, Histological alterations and immune response in the crayfish Procambarus clarkii given rVP28-incorporated diets, Fish Shellfish Immunol. 31 (2011) 1122-1128.

[27] J. Witteveldt, C.C. Cifuentes, J.M. Vlak, M.C. Van Hulten, Protection of Penaeus monodon against white spot syndrome virus by oral vaccination, J. Virol. 78 (2004) 2057-2061.

[28] B. Vaseeharan, T.P. Anand, T. Murugan, J.C. Chen, Shrimp vaccination trials with the VP292 protein of white spot syndrome virus, Lett. Appl. Microbiol. 43 (2006) 137-142.

[29] Y.M. Ha, G. Soo-Jung, N. Thi-Hoai, C.H. Ra, K.H. Kim, Y.K. Nam, et al., Vaccination of shrimp (Penaeus chinensis) against white spot syndrome virus (WSSV), J. Microbiol. Biotechnol. 18 (2008) 964-967.

[30] A. Thomas, N.S. Sudheer, K. Viswanathan, V. Kiron, I.S. Bright Singh, R.B. Narayanan, Immunogenicity and protective efficacy of a major white spot syndrome virus (WSSV) envelope protein VP24 expressed in Escherichia coli against WSSV, J. Invertebr. Pathol. 123 (2014) 17-24.

[31] Y.J. Lee, L.L. Chen, WSSV envelope protein VP51B links structural protein complexes and may mediate virus infection, J. 
Fish Dis. (2016) [Epub ahead of print].

[32] Y. Zhang, J.F. Ning, X.Q. Qu, X.L. Meng, J.P. Xu, TAT-mediated oral subunit vaccine against white spot syndrome virus in crayfish, J. Virol. Methods 181(2012) 59-67.

[33] A.T. Nguyen, C.K. Pham, H.T. Pham, H.L. Pham, A.H. Nguyen, L.T. Dang, et al., Bacillus subtilis spores expressing the VP28 antigen: a potential oral treatment to protect Litopenaeus vannamei against white spot syndrome, FEMS Microbiol. Lett. 358 (2014) 202-208.

[34] D. Ning, X. Leng, Q. Li, W. Xu, Surface-displayed VP28 on Bacillus subtilis spores induce protection against white spot syndrome virus in crayfish by oral administration, J. Appl. Microbiol. 111 (2011) 1327-1336.

[35] J. Melena, B. Bayot, I. Betancourt, Y. Amano, F. Panchana, V. Alday, et al., Pre-exposure to infectious hypodermal and haematopoietic necrosis virus or to inactivated white spot syndrome virus (WSSV) confers protection against WSSV in Penaeus vannamei (Boone) post-larvae, J. Fish Dis. 29 (2016) 589-600.

[36] F. Zhu, H. Du, Z.G. Miao, H.Z. Quan, Z.R. Xu, Protection of Procambarus clarkii against white spot syndrome virus using inactivated WSSV, Fish Shellfish Immunol. 26 (2009) 685-690.

[37] E.C. Amar, J.P. Faisan, Efficacy of an inactivated vaccine and nutritional additives against white spot syndrome virus (WSSV) in shrimp (Penaeus monodon), Isr. J. Aquacult-Bamid. 63 (2011) 1-9.

[38] M. Pathan, P. Gireesh-Babu, A. Pavan-Kumar, K. Jeena, R. Sharma, M. Makesh, et al., In vivo therapeutic efficacy of recombinant Penaeus monodon antiviral protein (rPmAV) administered in three different forms to WSSV infected Penaeus monodon, Aquaculture 376-379 (2013) 64-67.

[39] X.A. Li, Q.H. Liu, L. Hou, J. Huang, Effect of VP28 DNA vaccine on white spot syndrome virus in Litopenaeus vannamei, Aquacult. Int. 18 (2010) 1035-1044.

[40] R. Das, S. Karthireddy, P. Gireesh-Babu, A.K. Reddy, G. Krishna, A. Chaudhari, Protection of Penaeus monodon from infection of white spot syndrome virus by DNA construct expressing long hairpin-RNA against ICP11 gene, Indian J. Virol. $21(2010) 95-102$.

[41] Y. Mu, J.F. Lan, X.W. Zhang, X.W. Wang, X.F. Zhao, J.X. Wang, A vector that expresses VP28 of WSSV can protect red swamp crayfish from white spot disease, Dev. Comp. Immunol. 36 (2012) 442-449.

[42] S. Ahanger, S. Sandaka, D. Ananad, M.K. Mani, R. Kondadhasula, C.S. Reddy, et al., Protection of shrimp Penaeus monodon from WSSV infection using antisense constructs, Mar. Biotechnol. (NY) 16 (2014) 63-73.

[43] U. Khimmakthong, P. Deachamag, A. Phongdara, W. Chotigeat, Stimulating the immune response of Litopenaeus vannamei 
using the phagocytosis activating protein (PAP) gene, Fish Shellfish Immunol. 31 (2011) 415-422.

[44] P. Krishnan, P.G. Babu, S. Saravanan, K.V. Rajendran, A. Chaudhari, DNA constructs expressing long-hairpin RNA (lhRNA) protect Penaeus monodon against white spot syndrome virus, Vaccine 27 (2009) 3849-3855.

[45] S. Rajesh Kumar, V.P. Ishaq Ahamed, M. Sarathi, A. Nazeer Basha, A.S. Sahul Hameed, Immunological responses of Penaeus monodon to DNA vaccine and its efficacy to protect shrimp against white spot syndrome virus (WSSV), Fish Shellfish Immunol. 24 (2008) 467-478.

[46] T. Kono, K. Sonoda, Y. Kitao, T. Mekata, T. Itami, M. Sakai, The expression analysis of innate immune-related genes in kuruma shrimp Penaeus japonicus after DNA vaccination against penaeid rod-shaped DNA virus, JPN Soc. Fish Pathol. 44 (2009) 94-97.

[47] S. Rajeshkumar, C. Venkatesan, M. Sarathi, V. Sarathbabu, J. Thomas, K. Anver Basha, et al., Oral delivery of DNA construct using chitosan nanoparticles to protect the shrimp from white spot syndrome virus (WSSV), Fish Shellfish Immunol. 26 (2009) 429-437.

[48] J.F. Ning, W. Zhu, J.P. Xu, C.Y. Zheng, X.L. Meng, Oral delivery of DNA vaccine encoding VP28 against white spot syndrome virus in crayfish by attenuated Salmonella typhimurium, Vaccine 27 (2009) 1127-1135.

[49] J. Robalino, T. Bartlett, E. Shepard, S. Prior, G. Jaramillo, E. Scura, et al., Double-stranded RNA induces sequence-specific antiviral silencing in addition to nonspecific immunity in a marine shrimp: convergence of RNA interference and innate immunity in the invertebrate antiviral response? J. Virol. 79 (2005) 13561-13571.

[50] J. Xu, F. Han, X. Zhang, Silencing shrimp white spot syndrome virus (WSSV) genes by siRNA, Antiviral. Res. 73 (2007) $126-131$.

[51] P. Attasart, R. Kaewkhaw, C. Chimwai, U. Kongphom, O. Namramoon, S. Panyim, Inhibition of white spot syndrome virus replication in Penaeus monodon by combined silencing of viral rr2 and shrimp PmRab7, Virus Res. 145 (2009) 127-133.

[52] M. Sanjuktha, V. Stalin Raj, K. Aravindan, S.V. Alavandi, M. Poornima, T.C. Santiago, Comparative efficacy of double-stranded RNAs targeting WSSV structural and nonstructural genes in controlling viral multiplication in Penaeus monodon, Arch. Virol. 157 (2012) 993-998.

[53] R. Sudhakaran, T. Mekata, T. Kono1, M. Inada, S. Okugawa, M. Yoshimine, et al., Double-stranded RNA-mediated silencing of the white spot syndrome virus VP28 gene in kuruma shrimp, Marsupenaeus japonicus, Aquacult. Res. 42 (2011) 1153-1162.

[54] C.H. Mejía-Ruíz, S. Vega-Peña, P. Alvarez-Ruiz, C.M. Escobedo-Bonilla, Double-stranded RNA against white spot syndrome virus (WSSV) vp28 or vp26 reduced susceptibility of Litopenaeus vannamei to WSSV, and survivors exhibited 
decreased susceptibility in subsequent re-infections, J. Invertebr. Pathol. 107 (2011) 65-68.

[55] M. Sarathi, M.C. Simon, C. Venkatesan, A.S. Hameed, Oral administration of bacterially expressed VP28 dsRNA to protect Penaeus monodon from white spot syndrome virus, Mar. Biotechnol. (NY) 10 (2008) 242-249.

[56] M.F. Freeman, J.W. Tukey, Transformations related to the angular and the square root, Ann. Math. Stat. (1950) 607-611.

[57] W. Viechtbauer, Conducting meta-analyses in R with the metafor package, J. Stat. Softw. 36 (2010) 1-48.

[58] F. Abedini, M. Ebrahimi, H. Hosseinkhani, Technology of RNA interference in advanced medicine, Microrna. (2018) [Epub ahead of print]

[59] G. Solís-Lucero, K. Manoutcharian, J. Hernández-López, F. Ascencio, Injected phage displayed VP28 vaccine reduces shrimp Litopenaeus vannamei mortality by white spot syndrome virus infection, Fish Shellfish Immunol. 55 (2016) $401-406$.

[60] K.Q. Wei, J.X. Yang, Histological alterations and immune response in the crayfish Procambarus clarkii given rVP28-incorporated diets, Fish Shellfish Immunol. 31 (2011) 1122-1128. 